\title{
H And T-Slotted Rectangular Microstrip Patch Antennas for Wireless Communication
}

\author{
Gurpreet Kaur \\ M.tech Scholar \\ Yadavindra College of Engineering \\ Punjabi University GuruKashi Campus \\ Talwandi Sabo, Punjab, India
}

\author{
Jagtar Singh \\ Associate Professor ECE \\ Yadavindra College of Engineering \\ Punjabi University GuruKashi Campus \\ Talwandi Sabo, Punjab, India
}

\begin{abstract}
This paper describes the design of $\mathrm{H}$ and $\mathrm{T}$-Slotted Rectangular Microstrip Patch Antennas (RMPA) which resonates at a frequency of $f_{o}=2.4 \mathrm{GHz}$. The FR4 glass Epoxy with relative permittivity 4.4 and height $1.6 \mathrm{~mm}$ is used as substrate material. Antenna is fed by coaxial probe feed and simulated using HFSS. This antenna used to various wireless applications such as WiMAX, Wi-Fi, and Digital Multimedia Broadcasting (DMB) e.g.TV, etc.
\end{abstract}

\section{Keywords}

Gain, HFSS, Return loss, RMPA, VSWR.

\section{INTRODUCTION}

Microstrip antennas are designed to have many geometrical shapes and dimensions but rectangular and circular microstrip patches have been used in many application. The microstrip patch is preferred antenna structures for low cost, low profile, light weight, conformal shaping, high efficiency and compact design for the wireless system. These antennas are popular for low profile applications at frequency above $100 \mathrm{MHz}$ [8]. A microstrip patch antenna in its simplest form consists of a radiating patch on one side of a dielectric substrate and a ground plane on the other side [1]. It consists of a flat rectangular sheet or "patch" of metal, mounted over a larger sheet of metal called a ground plane [7].The rectangular microstrip patch antenna is made of a rectangular patch with dimensions width (W) and length (L) over a ground plane with a substrate thickness (h).

The patch may be square, rectangular, dipole, circular, triangular, circular ring, elliptical or any other configuration [2].

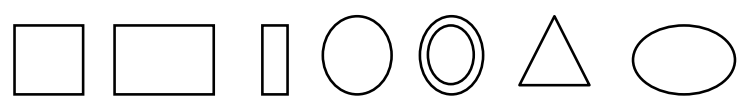

Fig 1: Common available shapes of Microstrip [2]

Their dielectric constants are usually in the range of $2.2<\varepsilon_{\mathrm{r}}<$ 12. Microstrip patch antenna are used for mobile phones, satellites, radio, radars, global positioning system (GPS), television, multiple input multiple output (MIMO), radio frequency identification (RFID),medical imaging and guidance of missiles are few examples of the military and industrial applications [3]. Microstrip antennas are most popular because of its numerous advantages in wireless communication systems that typically require antennas with small size, light weight, low profile, and low cost, and that are easy to fabricate and assemble [6].Now-a-days, antennas with multiband capabilities have been widely required in satellite and mobile communication systems to meet the growing system complexity [5]. A good design of the antenna can relax system requirements and improve overall system performance. With the available modern day services such as on the move internet browsing, e-banking, digital cable TV, etc.

Many of these feeding techniques can improve the bandwidth, but provide asymmetry in radiation pattern. Mostly aperture and electromagnetic coupling methods of feeding are used in stacked configurations to avoid the spurious radiations from the feed. The coaxial probe feed is the most popular one for electrically thick substrates; but the inductance of the probe may create the impedance mismatch which can be compensated by cutting slots on the patch. In this paper coaxial probe feeding, slot on the patch provide the gain enhancement [4]

\section{GEOMETRY OF MICROSTRIP PATCH ANTENNA}

Methods to feed microstrip antenna are microstrip line, coaxial probe, aperture coupling and proximity coupling [9]. All In this design coaxial probe feed technique is used as it is advantageous in small size applications.

The $\mathrm{H}$ and T-slotted microstrip patch antenna is designed based on three parameters. The substrate used is FR4 which has a dielectric constant of $\varepsilon_{\mathrm{r}}=4.4$ and height, $\mathrm{h}=1.6 \mathrm{~mm}$. The frequency of interest was $f_{o}=2.4 \mathrm{GHz}$. The dimensions of patch are calculated using the formula as given below.

Width of the patch is calculated using equation as given in [2]

$W=$

$$
\frac{\mathrm{c}}{2 \mathrm{f}_{\mathrm{o}} \sqrt{\frac{\left.\varepsilon_{\mathrm{r}}+1\right)}{2}}}
$$

The effective dielectric constant of the microstrip antenna is determined using equation as given in [2]

$\varepsilon_{\text {reff }}=\frac{\varepsilon_{\mathrm{r}+1}}{2}+\frac{\varepsilon_{\mathrm{r}-1}}{2}\left[1+12 \frac{\mathrm{h}}{\mathrm{w}}\right]^{\frac{-1}{2}}$.

Calculation of the Effective length (Leff) by following equation as given in [2]

$$
\mathrm{L}_{\mathrm{eff}}=\frac{\mathrm{c}}{2 \mathrm{f}_{\mathrm{o}} \sqrt{\varepsilon_{\text {reff }}}}
$$

Calculation of the length extension $(\Delta L)$ by following equation as given in [2]

$$
\Delta \mathrm{L}=0.412 \mathrm{~h} \frac{\left(\varepsilon_{\text {reff }+0.3}\right)\left(\frac{\mathrm{W}}{\mathrm{h}}+0.264\right)}{\left(\varepsilon_{\text {reff }}-0.258\right)\left(\frac{\mathrm{W}}{\mathrm{h}}+0.8\right)} .
$$

Length of the patch is calculated by following equation as given in [2]

$\mathrm{L}=L_{e f f}-2 \Delta \mathrm{L}$ 
Table 1. Patch dimensions

\begin{tabular}{|c|c|}
\hline $\begin{array}{c}\text { Dielectric Substrate } \\
\text { (FR4) }\end{array}$ & $\varepsilon r=4.4$ \\
\hline Substrate height (h) & $1.6 \mathrm{~mm}$ \\
\hline Patch width (W) & $38.04 \mathrm{~mm}$ \\
\hline Patch length (L) & $29.44 \mathrm{~mm}$ \\
\hline
\end{tabular}

\section{ANTENNA DESIGN PARAMETERS}

The dielectric constant of the substrate is closely related to the size and the bandwidth of the microstrip antenna. Low dielectric constant of the substrate produces larger bandwidth, while the high dielectric constant of the substrate results in smaller size of antenna. A trade-off relationship exists between antenna size and bandwidth [4].

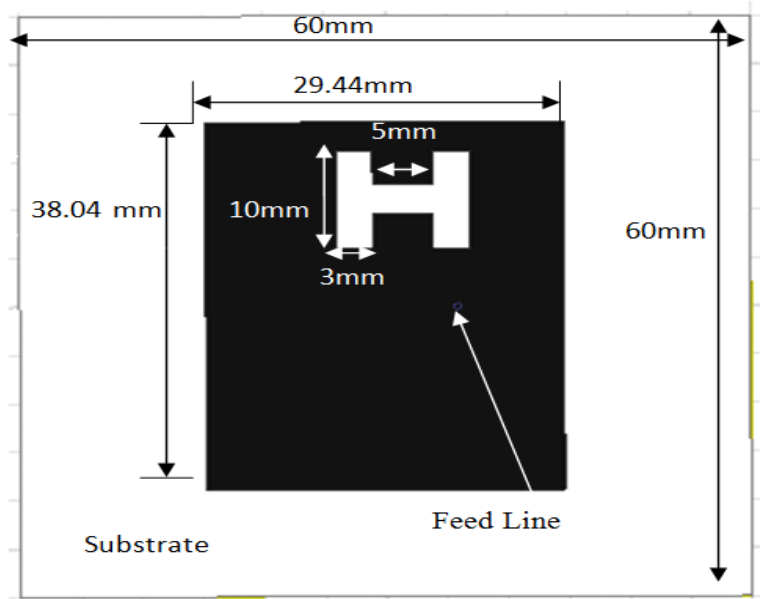

Fig 2: Geometry of RMPA with H slot

Fig 2 and Fig 3 show the top view of the $\mathrm{H}$-shape and T-shape patch antenna designed on HFSS (High frequency Structure Simulator) software. HFSS is a higher awarding full wave electromagnetic (EM) field simulator for random 3D volumetric inactive device model that takes advantage of the well-known Microsoft Windows graphical user interface.

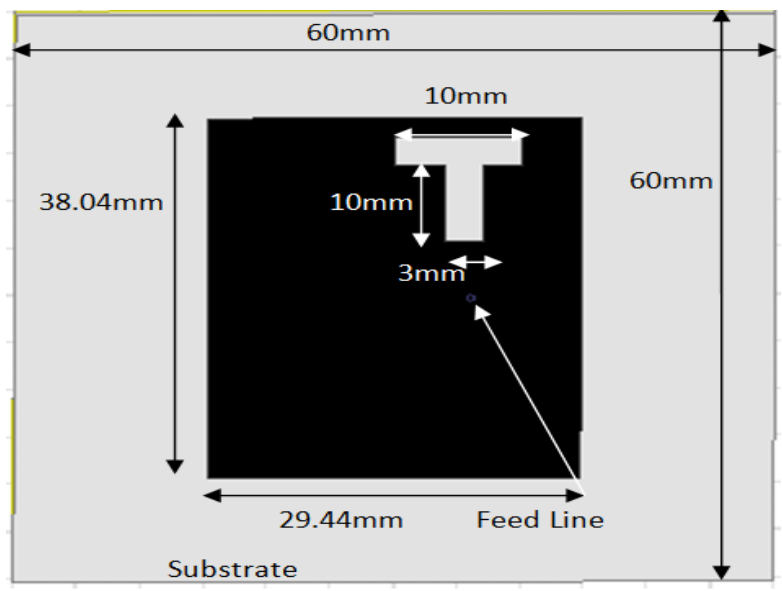

Fig 3: Geometry of RMPA with T slot

\section{SIMULATION RESULTS}

\subsection{Return loss}

Return loss versus frequency plot of $\mathrm{H}$ \& $\mathrm{T}$ - Slotted Rectangular Microstrip Patch Antennas are shown in figure 4 $\&$ figure 5 respectively.



Fig 4: Return loss versus frequency plot with H-slot RMPA

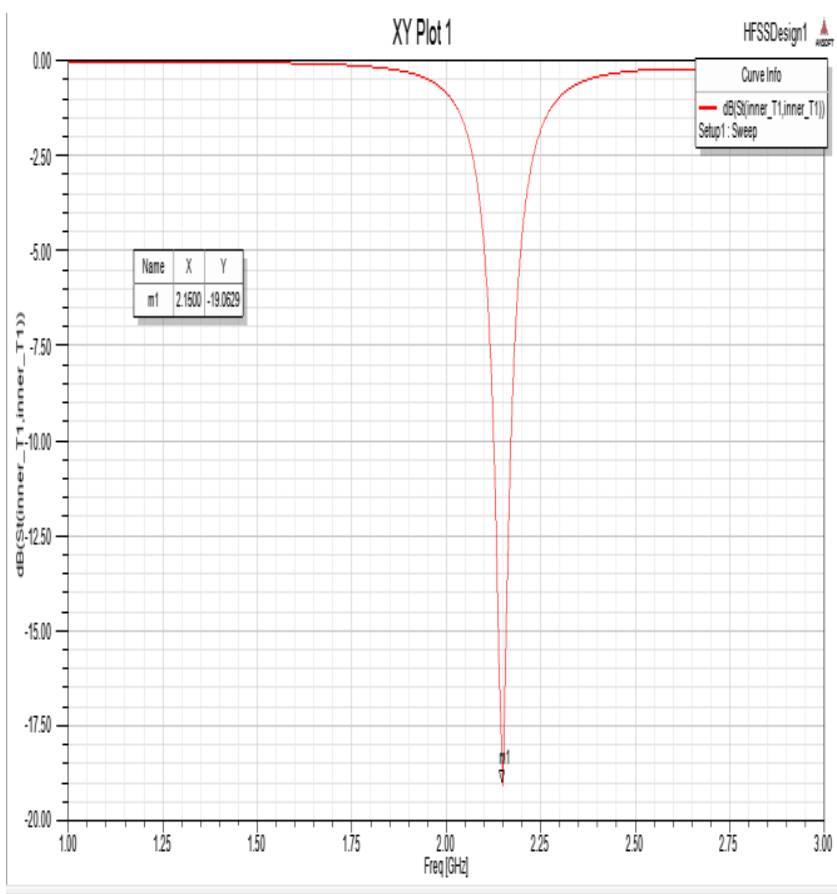

Fig 5: Return loss versus frequency plot with T-slot RMPA 


\subsection{Gain}

Three dimension radiation pattern of $\mathrm{H} \& \mathrm{~T}$ slotted Rectangular Microstrip Patch Antennas at $2.4 \mathrm{GHz}$ are shown in figure $6 \& 7$ respectively. From Figure 6 it is clear that $\mathrm{H}-$ slot Rectangular Microstrip Patch Antenna has a gain of $8.21 \mathrm{~dB}$, on the other hand T slot Rectangular Microstrip Patch Antenna has a gain of $6.90 \mathrm{~dB}$.
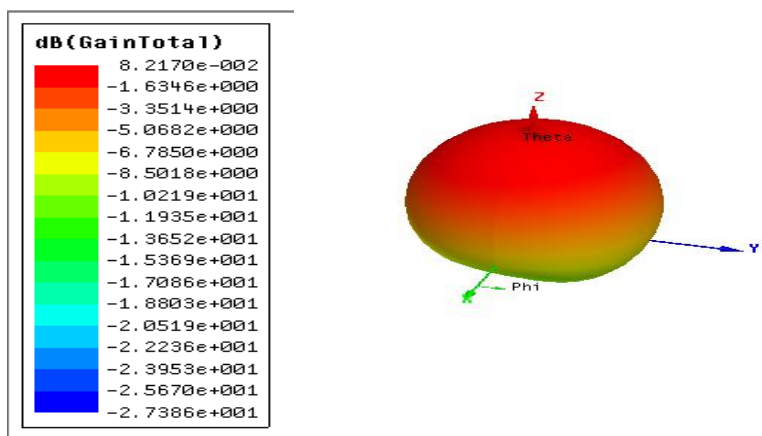

Fig 6: Three dimension radiation pattern of $\mathrm{H}$-slot RMPA


Fig 7: Three dimension radiation pattern of $\mathrm{T}$-slot RMPA

Table 2. Performance parameters of $\mathbf{H} \& \mathrm{~T}$ - Slotted Rectangular Microstrip Patch Antennas at $2.4 \mathrm{GHz}$

\begin{tabular}{|c|c|c|c|}
\hline $\begin{array}{c}\text { Designed } \\
\text { antenna }\end{array}$ & $\begin{array}{c}\text { Return } \\
\text { loss }\end{array}$ & Gain & VSWR \\
\hline $\begin{array}{c}\text { H -shape } \\
\text { slot }\end{array}$ & $-22.18 \mathrm{~dB}$ & $8.21 \mathrm{~dB}$ & 1.16 \\
\hline $\begin{array}{c}\mathrm{T} \text {-shape } \\
\text { slot }\end{array}$ & $-19.06 \mathrm{~dB}$ & $6.90 \mathrm{~dB}$ & 1.25 \\
\hline
\end{tabular}

\section{VSWR}

Voltage Standing Wave Ratio (VSWR) verses frequency plot for H \& T- Slotted Rectangular Microstrip Patch Antennas are shown in figure $8 \& 9$ respectively. The values of VSWR for both antennas are shown in Table 2 .

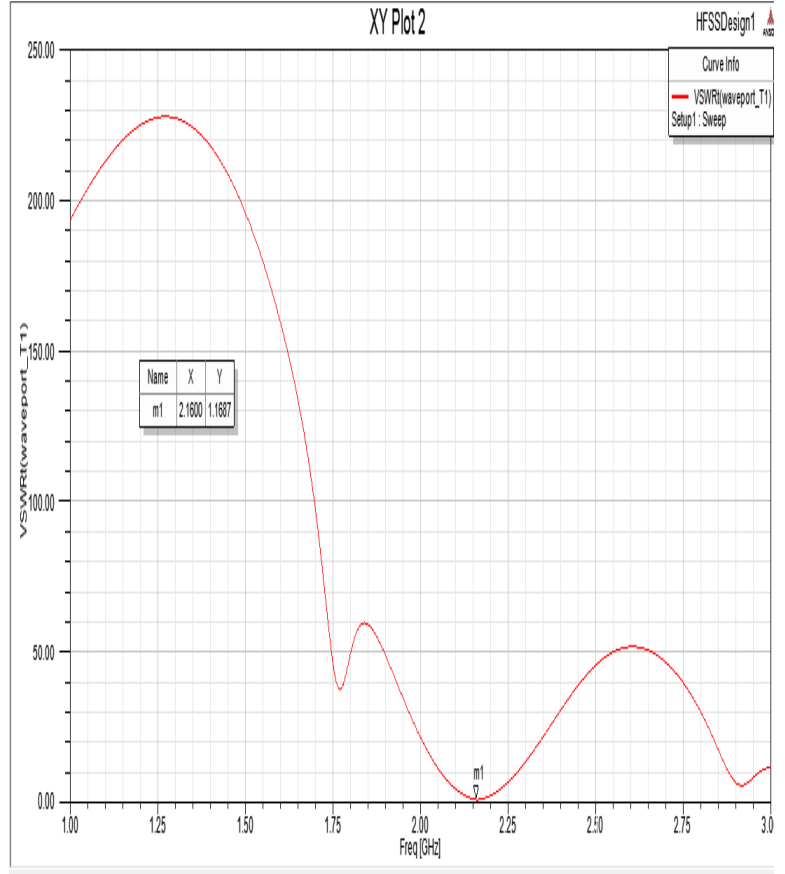

Fig 8: VSWR versus Frequency plot of $\mathrm{H}$ slot RMPA

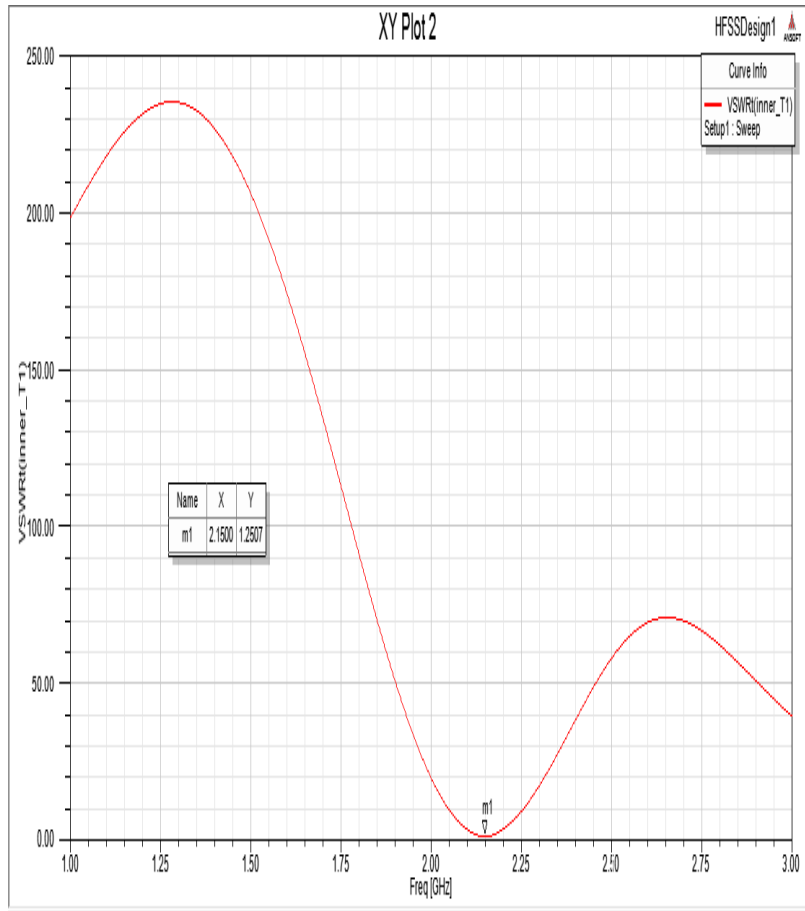

Fig 9: VSWR versus Frequency plot of T slot RMPA

\section{CONCLUSION}

In this paper, H \& T- Slotted Rectangular Microstrip Patch Antenna's are designed. These antennas operate frequency at $2.4 \mathrm{GHz}$. From the Three dimension radiation plot it is clear that $\mathrm{H}$ - slot antenna has $8.21 \mathrm{~dB}$ gain where as T- slot antenna has $6.90 \mathrm{~dB}$. Thus it is conclusion that $\mathrm{H}$ - slotted Rectangular 
Microstrip Patch Antenna better performance than T-slotted Rectangular Microstrip Patch Antenna.

Both antennas are used for various wireless applications such as WiMAX, Wi-Fi, and Digital Multimedia Broadcasting (DMB) e.g.TV, etc.

[9] Singh, J., Singh, A.P. and Kamal T.S., "On the design of Triangular Microstrip Antenna for Wireless Communication", International Journal of Computer Applications, pp. 103-106, October 2011

\section{REFERENCES}

[1] Sharma, B.S. and Panwar, S. "Dual U-slot Microstrip Patch Antenna With Enhanced Bandwidth," International Journal of Science and Research (IJSR), Volume 2 Issue 8, pp. 145-147, August 2013.

[2] Balanis,C. A. Antenna Theory, John Wiley \& Sons, Inc., 1997.

[3] Motin, M. A., Hassan, Md. Imran and Islam, Md. S., "Design And Simulation Of a Low Cost Three Band Microstrip Patch Antenna for the X-band, Ku- Band and K- Band Applications," $7^{\text {th }}$ International Conference on Electrical and Computer Engineering, pp.397-400, 20-22 December, 2012 IEEE.
[4] Kushwaha, R.S., Srivastava, D.K. and Saini, J.P.,"A Design of $\mathrm{H}$-shape Slot loaded Wideband Microstrip Patch Antenna," International Journal of Electronics and Computer Science Engineering, Volume 1,N2,pp: 533 537, 26 June 2012.

[5] Panusa, S. and Kumar, M. "Quad Band H-slot Microstrip Patch Antenna for WiMAX Application," International Journal of Computer Applications, Volume 103 - No.12, October 2014.

[6] Tarange, V., Gite, T., Musale, P. and Khobragade, S. V., "A U- Slotted H- Shaped Microstrip Antenna with Capacitive Feed For Broadband Application," International Conference on Emerging Trends in Networks and Computer Communications, pp. 182-184, April 2011 IEEE.

[7] Kumar, Y. and Kaur, S. "Optimization of U-slot microstrip patch antenna using genetic algorithm," IJRITCC, volume 1, issue 10, October 2013.

[8] Sivia,J.S., Singh, A. and kamal,T.S.,"neurocomputational approach for feed-position estimation in circular microstrip Antenna," International Journal of Computer Applications, Volume 75- No.6, pp: 33-38, August 2013. 